\title{
Bridging the Confidence Gap: Raising Self-Efficacy Amongst Urban High School Girls Through STEM Education
}

\author{
Rosellen Roche*1 and Joel Manzi ${ }^{2}$ \\ ${ }^{1}$ Department of Family Medicine, Ohio University, USA \\ ${ }^{2}$ Department of Family Medicine, Ohio University, USA
}

*Corresponding author: Rosellen Roche, Department of Family Medicine, Ohio University, USA.

To Cite This Article: Rosellen Roche. Bridging the Confidence Gap: Raising Self-Efficacy Amongst Urban High School Girls Through STEM Education. Am J Biomed Sci \& Res. 2019 - 5(6). AJBSR.MS.ID.000964. DOI: 10.34297/AJBSR.2019.05.000964.

Received: 眥 October 09, 2019; Published: 㘹 October 18, 2019

\begin{abstract}
Careers in science, technology, engineering and mathematics (STEM) represent one of the fastest growing segments of the global economy. Notably underrepresented in this wave of new job creation are ethnic minorities and women. To meet the growing workforce demands, educators are creating a number of new educational interventions aimed at encouraging young people towards careers in STEM. However, many programs do not contain a component that actively engages female learners, especial female students of color. An emerging number of interventions are now being staged specifically catering to the interests and aptitudes of female STEM students of color. Within many of these programs, the primary outcomes measured are still related to test scores, university matriculation, and career placement. In this mini-review, the authors posit that selfefficacy is a much more appropriate metric by which to gauge the success of STEM interventions.
\end{abstract}

Keywords: STEM, Secondary Education, Medicine, Self-efficacy, Career Development

Abbreviations: STEM: Science Technology Engineering Mathematics

\section{Introduction}

In accordance with current global economic trends, the largest and fastest growing job sector in the United States revolves around Science, Technology, Engineering, and Mathematics (STEM) occupations [1]. Many of these careers require at least a bachelor's degree or higher in addition to a significant broad understanding of multidisciplinary concepts across the fields of science, technology, and mathematics. In response to the growing employment opportunities and global market competition, STEM education has become a priority on national, regional, state, and local community levels [2]. Schools across the country have revamped their curricula to integrate STEM concepts at younger and younger levels, often using the term "pipeline" to describe the early exposure of STEM principles from primary education to secondary education, university, and career placement [3]. The integration of STEM into curriculum has been undertaken in many ways, including but not limited to: STEM focused charter schools [4,5] STEM-based elective courses or tracks [6], after-school STEM clubs [7], summer intensive camp-style STEM interventions [8], online STEM education and mentoring programs [9], or off-campus collaborations with local businesses and universities [10].

These educational interventions have been promoted as success stories for the innovative curriculum and preparing students for high paying careers in STEM fields. An increasing number of these programs are designed to target urban youth who live in or around the poverty level [7]. STEM education is often described as an element of urban renewal that provides at-risk students with an opportunity to better prepare themselves for the increasingly competitive jobs market and become high wage earners [11]. Within STEM fields, there is a significant underrepresentation of ethnic minority workers [12,13]. While the success of STEM based educational interventions varies, early findings from studies of high-quality STEM education appear promising [14,15].

\section{Women of color in STEM}

Despitemanylarge scaled efforts, there isalsoa disproportionally small number of women working in many STEM arenas. When 
observed in conjunction with race, women of color are the least likely segment of the US population to be employed in STEM [16]. Despite historical narratives of women of color participating in early technological advances (see the 2016 film Hidden Figures for example) or national Public Service Announcements highlighting female scientists and engineers of color, the public perception of the STEM fields is significantly lacking in minority female representation [17].

Traditional STEM based educational interventions have not included programming directed towards female students and their outside interests [18]. While this is often done in an attempt toward gender neutrality, underlying stereotypes often leave female students feeling ignored or disinterested in pursuing further STEM studies [19]. This issue contributes to what some researchers have called the "leaking pipeline" [20]. While female students may receive initial exposure to STEM concepts and programming, these programs are less likely to result in female students pursuing further STEM studies or careers. This alarming pattern is even further exacerbated among female students of color who feel even more alienated from the unintentionally perpetuated stereotypes of the STEM fields [21]. A growing number of educational programs are being developed to help address this disproportionality and encourage female students of color to choose paths of study that lead to careers in STEM $[22,23]$. These programs often include specific learning components such as female scientist role models and mentorship, application of STEM to individual interests outside the classroom, culturally relevant activities, and an element of social engagement with other female students $[10,24,25]$. In comparison to mix gendered classrooms or gender neutral curriculum, these programs show an exceptional success rate at encouraging female students to pursue STEM [26].

\section{STEM education as a mechanism of raising self- efficacy}

While the primary outcome measured for determining the success of many of these programs is the rate at which participant pursue high education in STEM or enter into STEM fields, there is often more than one meaningful outcome. A potentially overlooked outcome of the success, or lack-thereof, observed in a particular program is the development of self-efficacy [27]. As first described by the psychologist Albert Bandura, self-efficacy is a person's perceived ability to successfully execute the actions necessary to deal with prospective situations [28]. When a person has a higher level self-efficacy, they will be more likely to succeed at perceived challenges or obstacles. Regardless of technical ability, selfefficacy measures the internal motivating factors and perceptions of one's ability to succeed. Though not exclusive to educational settings, self-efficacy has been studied as a quantitative marker of internal attitudes and dynamic changes resultant from educational interventions $[27,29]$. However, in many educational environments, female students and minority students often report lower levels of self-efficacy in relation to their male and/or racial majority contemporaries; especially inregards to their capabilities in STEM [30].

Intrinsic to self-efficacy is the ability to solve complex problems and have confidence regarding the ability to succeed at solving the problem. Problem solving is inherent to STEM. Therefore, successful STEM based interventions should improve a student's ability to solve complex problems. With each successful repetition of a problem and solution, an incremental increase in self-efficacy should also be observed. The authors posit that it is the increase in self-efficacy that will increase the likelihood of female students actually pursuing careers in STEM.

\section{Conclusion: planning for meaningful programmatic outcomes}

In order to most successfully meet the objective of increasing the number of women of color in STEM, educators should actively seek out ways to increase self-efficacy in their students. In addition to the valuable curricular components that specifically engage with the interests of female students of color, educators should be cognizant of the impact that STEM education can have on self-efficacy and intentionally cultivate an environment that promotes self-efficacy. While traditional programmatic outcomes measured include college admissions test scores, high education degree completion or workforce entry, there are often few realtime markers available to gauge the efficacy of the STEM based educational interventions. These outcomes often manifest several years after an intervention has occurred, which poses a distinct challenge to educators. The effectiveness of a program can often not be quantitatively measured until many years after the fact, leading to potentially sub-optimal programming for prolonged periods of time. Measuring self-efficacy gives educators a meaningful outcome that does not require multiple years to come to fruition. STEM based interventions must first successfully impact self-efficacy in order to increase the levels of STEM participation by female students of color that is needed to diversify the STEM workforce.

Conflict of Interest: none to declare.

\section{References}

1. S Fayer, A Lacey, A Watson (2017) STEM Occupations: Past, Present, And Future. US Bureau of Labor Statistics,USA.

2. T Wackler, C Kontos (2018) Charting a Course for Success: America's Strategy for STEM Education. National Science and Technology Council Official Government Report, USA.

3. GH Lyon, J Jafri, KathleenSt Louis (2012) Beyond the Pipeline: STEM Pathways for Youth Development. Afterschool Matters, USA.

4. S J Lynch, T Behrend, EP Burton, B Means (2013) Inclusive STEM-focused high schools: STEM education policy and opportunity structures. in annual conference of National Association for Research in Science Teaching (NARST), Rio Grande, Puerto Rico, USA.

5. M Hansen (2014) Characteristics of schools successful in STEM: Evidence from two states' longitudinal data. The Journal of Educational Research 107(5): 374-391. 
6. A Sahin (2013) STEM clubs and science fair competitions: Effects on post-secondary matriculation. J STEM Educ 14(5): 11.

7. M Koch, P Lundh, C J Harris (2019) Investigating STEM Support and Persistence Among Urban Teenage African American and Latina Girls Across Settings, Urban Education 54(2): 243-273.

8. AV Blue, ME Geesey, ME Sheridan, WT J Basco (2006) Performance Outcomes Associated with Medical School Community Service. Acad Med 81(10 Suppl): S79-82.

9. H Stoeger, X Duan, S Schirner, T Greindl, A Ziegler, et al. (2013) The effectiveness of a one-year online mentoring program for girls in STEM. Computers \& Education 69: 408-418.

10. NS King, RM Pringle (2019) Black girls speak STEM: Counterstories of informal and formal learning experiences. J Res Sci Teach 56(5): 539569.

11. EC Bullock (2017) Only STEM Can Save Us? Examining Race, Place, and STEM Education as Property, Educational Studies 53(6): pp. 628-641.

12. R Hira (2010) US policy and the STEM workforce system. American Behavioral Scientist 53(7): pp. 949-961.

13. AL Griffith (2010) Persistence of women and minorities in STEM field majors: Is it the school that matters?. Econ Educ Rev 29(6): 911-922.

14. P Arcidiacono, EM Aucejo, VJ Hotz (2016) University differences in the graduation of minorities in STEM fields: Evidence from California. The American Economic Review 106(3): 525-562.

15. S Hurtado, CB Newman, MC Tran, MJ Chang (2010) Improving the rate of success for underrepresented racial minorities in STEM fields: Insights from a national project," New Directions Institutional Research 148: $5-15$.

16. L Charleston, RP Adserias, N Lang, J Jackson (2014) Intersectionality and STEM: The role of race and gender in the academic pursuits of African American women in STEM. J Progress Policy Pract 2(3): 273-293.

17. JL Levere (2018) Role Models Tell Girls That STEM's for Them in New Campaign. The New York Times,USA

18. JS Boston, A Cimpian (2018) How Do We Encourage Gifted Girls to Pursue and Succeed in Science and Engineering?. Gift Child Today 41(4): 196-207.
19. T Sengupta-Irving, S Vossoughi (2019) Not in their name: re-interpreting discourses of STEM learning through the subjective experiences of minoritized girls. Race Ethnicity and Education 22(4): 479-501.

20. A Reinking, B Martin (2018) The Gender Gap in STEM Fields: Theories, Movements, and Ideas to Engage Girls in STEM Journal of New Approaches in Educational Research 7(2): 148-153.

21. David L Blustein, Michael Barnett, Sheron Mark, Mark Depot, Meghan Lovering, et al. (2013) Examining Urban Students' Constructions of a STEM/Career Development Intervention Over Time Journal of Career Development 40(1): 40-67.

22. HS Mosatche, S Matloff-Nieves, L Kekelis, EK Lawner (2013) Effective STEM Programs for Adolescent Girls: Three Approaches and Many Lessons Learned. Afterschool Matters, USA

23. KA Scott, MAWhite (2013) COMPUGIRLS' Standpoint: Culturally Responsive Computing and Its Effect on Girls of Color. Urban Education 48(5): 657-681.

24. JL Young, JR Young, DY Ford (2019) Culturally Relevant STEM Out-ofSchool Time: A Rationale to Support Gifted Girls of Color. Roeper Review 41(1): 8-19.

25. ZR Khan, G Rodrigues (2017) Stem for Girls from Low Income Families: Making Dreams Come True. J Dev Areas 51(2): 435-448.

26. N Dasgupta, JG Stout (2014) Girls and women in science, technology, engineering, and mathematics: STEMing the tide and broadening participation in STEM careers. Policy Insights from the Behavioral and Brain Sciences (1): 21-29.

27. LD Falco, JJ Summers (2019) Improving Career Decision Self-Efficacy and STEM Self-Efficacy in High School Girls: Evaluation of an Intervention. J Career Dev 46(1): 62-76.

28. A Bandura (1982) Self-efficacy mehanism in human agency. American Psychologist 37(2): 122

29. A Bandura (1993) Perceived Self-Efficacy in Cognitive Development and Functioning Educational Psychologist 28(2): 117-148.

30. JV Patterson, AT Johnson (2017) High School Girls' Negotiation of Perceived Self-Efficacy and Science Course Trajectories. Journal of Research in Education 27(1): 79-113. 